\title{
Naphthazarin suppresses cell proliferation and induces apoptosis in human colorectal cancer cells via the B-cell lymphoma 2/B-cell associated $X$ protein signaling pathway
}

\author{
AI-DONG CHEN ${ }^{1}, \mathrm{HUI} \mathrm{LI}^{2}$, YONG-CHUN LI ${ }^{3}$ and HAI ZENG ${ }^{3}$ \\ Departments of ${ }^{1}$ Gastroenterology, ${ }^{2}$ Medical Oncology and ${ }^{3}$ Second General Surgery, \\ Hongqi Hospital Affiliated to Mudanjiang Medical University, Mudanjiang, Heilongjiang 157011, P.R. China
}

Received May 1,2015; Accepted September 9, 2016

DOI: $10.3892 / 01.2016 .5319$

\begin{abstract}
Colorectal cancer is the most common gastrointestinal cancer in the USA. Naphthazarin, one of the naturally available 1,4-naphthoquinone derivatives, is a natural bioactive molecule that exhibits an antitumor effect. To the best of our knowledge, this is the first study to investigate the anticancer effect of naphthazarin on cell proliferation and apoptosis in human SW480 colorectal cancer cells. In the present study, 3-(4,5-dimethylthiazol-2-yl)-2,5-diphenyltetrazolium bromide and lactate dehydrogenase assays were performed to assess the effect of napthazarin on cell proliferation and cytotoxicity of SW430 cells, respectively. In addition, an Annexin V-fluorescein isothiocyanate/propidium iodide apoptosis assay and 4',6-diamidino-2-phenylindole staining were used to analyze cell and nuclei apoptosis of SW480 cells, respectively, following treatment with naphthazarin. Poly (ADP-ribose) polymerase (PARP), B-cell lymphoma 2 (Bcl-2) and B-cell associated $\mathrm{X}$ protein (Bax) protein expression was analyzed by western blot. Furthermore, caspase- 3 activation was analyzed using a commercial kit. The results revealed that naphthazarin exhibited cell growth inhibition, an increase in cytotoxicity and apoptosis induction in SW480 cells, which was associated with activation of the Bax/Bcl-2 signaling pathway and cleaved caspase-3 activation. However, no significant differences in PARP expression were identified following treatment with naphthazarin in SW480 cells. Taken together, these results suggest that naphthazarin decreased cell viability and induced apoptosis of SW480 cells, indicating that naphthazarin may present a potential therapeutic agent for human colorectal cancer treatment.
\end{abstract}

Correspondence to: Mr. Hai Zeng, Department of Second General Surgery, Hongqi Hospital Affiliated to Mudanjiang Medical University, 5 Tongxiang Street, Aimin, Mudanjiang, Heilongjiang 157011, P.R. China

E-mail: qqhzengqq@163.com

Key words: naphthazarin, human colorectal cancer, B-cell lymphoma 2; B-cell associated X protein

\section{Introduction}

Colorectal cancer is the third and second most common malignant tumor in males and females worldwide, respectively (1). According to the International Agency for Research on Cancer, 1.2 million novel cases of colorectal cancer were diagnosed worldwide in 2008, accounting for $8 \%$ of all cancer-related mortalities $(2,3)$. The incidence of colorectal cancer is highest in developed countries and regions: Due to economic development and rapid urbanization in recent years in China, which has resulted in dietary and lifestyle changes within the population, the colorectal cancer morbidity and mortality rates in China are now higher than the average rates, worldwide $(4,5)$.

In 2013, the incidence of colorectal cancer was 45.1 per 100,000 individuals, with $>5,000$ deaths per year and an average of 13.1 years of life lost (1). Colorectal cancer operation is an important method for the treatment of colorectal cancer (5). The clinical manifestations of colorectal cancer may appear in the following ways: Altered defecation habits, stomach ache, abdominal masses, gastrointestinal hemorrhage, jaundice and a change in character of the stool. All patients have postoperative complications, with have a great impact on the patient's quality of life, and even endanger the patient's life (6). Therefore, it is important that physicians investigate multiple potential treatments for colorectal cancer, with the aim of preventing these treatment complications (7).

Naphthazarin is a natural bioactive substance present in numerous plants that has been demonstrated to exhibit antitumor effects (8). Naphthazarin is an important active ingredient, which exhibits extensive pharmacological activities, including antitumor activity, and due to its low toxicity, it has gained considerable attention $(9,10)$. However, to date the anticancer effects of naphthazarin on human colorectal cancer cells have not been reported. In the present study, the anticancer effects of naphthazarin, as well as its effect on the B-cell lymphoma 2 (Bcl-2)/B-cell associated X protein (Bax) signaling pathway were investigated in human SW480 colorectal cancer cells.

\section{Materials and methods}

Reagents. Dulbecco's modified Eagle's medium (DMEM), fetal bovine serum (FBS), naphthazarin (Fig. 1) and 
3-(4,5-dimethylthiazol-2-yl)-2,5-diphenyltetrazolium bromide (MTT) solution and a lactate dehydrogenase (LDH) assay were purchased from Sigma-Aldrich (Merck Millipore, Darmstadt, Germany). Annexin V-fluorescein isothiocyanate (FITC)/propidium iodide (PI) apoptosis and caspase-3 activation kits were purchased from KeyGen Biotech Co., Ltd., (Nanjing, China).

Cell culture and cell viability assay. The human colorectal cancer SW480 cell line was obtained from the Cell Bank of Chinese Academy of Sciences (Shanghai, China) and maintained in DMEM (Sigma-Aldrich; Merck Millipore) supplemented with $10 \%$ FBS in a humidified atmosphere of $5 \% \mathrm{CO}_{2}$ at $37^{\circ} \mathrm{C}$. A total of $1 \times 10^{4}$ cells/well were seeded in a 96-well plate and incubated at $37^{\circ} \mathrm{C}$ in a $5 \% \mathrm{CO}_{2}$ incubator for $24 \mathrm{~h}$. After incubation, SW480 cells were treated with $0,0.5$, 1, 5, 10 and $20 \mu \mathrm{M}$ naphthazarin for $24 \mathrm{~h}$. Subsequently, $20 \mu \mathrm{l}$ MTT solution (Sigma-Aldrich; Merck Millipore) was added to each well and incubated at $37^{\circ} \mathrm{C}$ in a $5 \% \mathrm{CO}_{2}$ incubator for $4 \mathrm{~h}$. Following incubation, the culture medium was replaced and $200 \mu \mathrm{l}$ DMSO was added to each well and agitated for $20 \mathrm{~min}$ at room temperature. Cell viability was analyzed at a wavelength of $490 \mathrm{~nm}$ using an ELISA reader (Multiskan EX; Thermo Labsystems, Helsinki, Finland). .

LDH assay. SW480 cells $\left(1 \times 10^{4}\right.$ cells/well) were seeded in a 96-well plate and incubated at $37^{\circ} \mathrm{C}$ in a $5 \% \mathrm{CO}_{2}$ incubator for $24 \mathrm{~h}$. After incubation, SW480 cells were treated with to $0,0.5$, 1, 5, 10 and $20 \mu \mathrm{M}$ naphthazarin for $24 \mathrm{~h}$. Subsequently, $100 \mu \mathrm{l}$ LDH solution was added to each well and cultured for $30 \mathrm{~min}$. The absorbance was read at a wavelength of $490 \mathrm{~nm}$ using an ELISA reader (Multiskan EX; Thermo Labsystems).

Annexin V-FITC/PI apoptosis assay. SW480 cells $\left(1 \times 10^{6}\right.$ cells/well) were seeded in a 6 -well plate and incubated at $37^{\circ} \mathrm{C}$ in a $5 \% \mathrm{CO}_{2}$ incubator for $24 \mathrm{~h}$. After incubation, SW480 cells were treated with $0,0.5,1$ and $5 \mu \mathrm{M}$ naphthazarin for $24 \mathrm{~h}$. SW480 cells were trypsinized (Sangon Biotech Co., Ltd., Shanghai, China), washed with phosphate-buffered saline (PBS) and fixed in precooling $75 \%$ ethanol at $4^{\circ} \mathrm{C}$ overnight. Next, Annexin-V FITC and PI were added and incubated for $10 \mathrm{~min}$ at room temperature in the dark. Flow cytometry analysis was performed on a FACScan flow cytometer (BD Biosciences, San Diego, CA, USA) using emission filters of 525 and $575 \mathrm{~nm}$. Data were analyzed using CellQuest Pro software version 5.1 (BD Biosciences).

4',6-diamidino-2-phenylindole (DAPI) staining assay. SW480 cells $\left(1 \times 10^{6}\right.$ cells/well $)$ were seeded in a 6 -well plate and incubated at $37^{\circ} \mathrm{C}$ in a $5 \% \mathrm{CO}_{2}$ incubator for $24 \mathrm{~h}$. Following incubation, SW480 cells were treated with $0,0.5,1$ and $5 \mu \mathrm{M}$ naphthazarin for $24 \mathrm{~h}$. SW480 cells were then incubated with $0.1 \%$ sodium citrate containing $0.1 \%$ Triton X-100 (Beyotime Institute of Biotechnology, Haimen, China) for $5 \mathrm{~min}$ at $4^{\circ} \mathrm{C}$. Cell nuclei were observed using a fluorescent microscope (Zeiss Axio Observer A1; Carl Zeiss, Inc., Oberkochen, Germany).

Western blot analysis. SW480 cells $\left(1 \times 10^{6}\right.$ cells/well) were seeded in a 6 -well plate and incubated at $37^{\circ} \mathrm{C}$ in a $5 \% \mathrm{CO}_{2}$

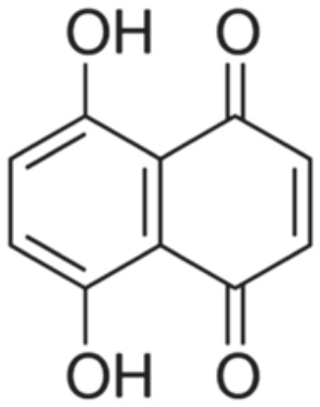

Figure 1. Chemical structure of naphthazarin.

incubator for $24 \mathrm{~h}$. After incubation, SW480 cells were treated with $0,0.5,1$ and $5 \mu \mathrm{M}$ naphthazarin for $24 \mathrm{~h}$. SW480 cells were harvested with PBS and extracted in cold radioimmunoprecipitation assay (RIPA) lysis buffer (Beyotime Institute of Biotechnology). Protein concentrations were determined using the by Pierce BCA protein assay kit (BD Biosciences). Equal amounts of protein were resolved on 6-15\% SDS-PAGE gel and transferred to polyvinylidene fluoride membranes (Santa Cruz Biotechnology, Inc., Santa Cruz, CA, USA). Membranes were then incubated with antibodies against poly (ADP-ribose) polymerase (PARP; 1:1,000; D161071; Santa Cruz Biotechnology, Inc.), Bax (1:500; AF0057; Beyotime Institute of Biotechnology), Bcl-2 (1:500; AF0060; Beyotime Institute of Biotechnology) and $\beta$-actin (1:500; AA128; Beyotime Institute of Biotechnology) overnight at $4^{\circ} \mathrm{C}$. Membranes were next washed with TBS containing Tween 20 and incubated with horseradish peroxidase-conjugated goat anti-rabbit immunoglobulin G (1:2,000; Sangon Biotech, Co., Ltd.) at $37^{\circ} \mathrm{C}$ for $2 \mathrm{~h}$. The protein band was detected using ImageLab 3.0 software (Bio-Rad Laboratories, Inc., Hercules, CA, USA).

Caspase- 3 activation assay. SW480 cells ( $1 \times 10^{6}$ cells/well) were seeded in a 6 -well plate and incubated at $37^{\circ} \mathrm{C}$ in a $5 \% \mathrm{CO}_{2}$ incubator for $24 \mathrm{~h}$. After incubation, SW480 cells were treated with $0,0.5,1$ and $5 \mu \mathrm{M}$ naphthazarin for $24 \mathrm{~h}$. SW480 cells were harvested with PBS and extracted in cold RIPA lysis buffer (Beyotime Institute of Biotechnology). Protein concentrations were determined using the Pierce BCA protein assay kit (BD Biosciences). Equal amounts of the total protein were mixed with Ac-DEVD-pNA (Beyotime Institute of Biotechnology) for caspase-3 expression and incubated at $37^{\circ} \mathrm{C}$ for $2 \mathrm{~h}$ in the dark. Caspase- 3 activation was analyzed at a wavelength of $405 \mathrm{~nm}$ using an ELISA reader (Multiskan EX; Thermo Labsystems).

Statistical analysis. Data are presented as the mean \pm standard deviation of three independent experiments. Differences between groups were analyzed using the Student's t-test and the SPSS 17.0 program (SPSS, Inc., Chicago, IL, USA). P<0.05 was considered to indicate a statistically significant difference.

\section{Results}

Naphthazarin decreases SW480 cell viability. The effect of naphthazarin on cell viability was investigated by MTT assay in SW480 cells. Following treatment with 5, 10 and $20 \mu \mathrm{M}$ naphthazarin significantly decreased cell viability of SW480 


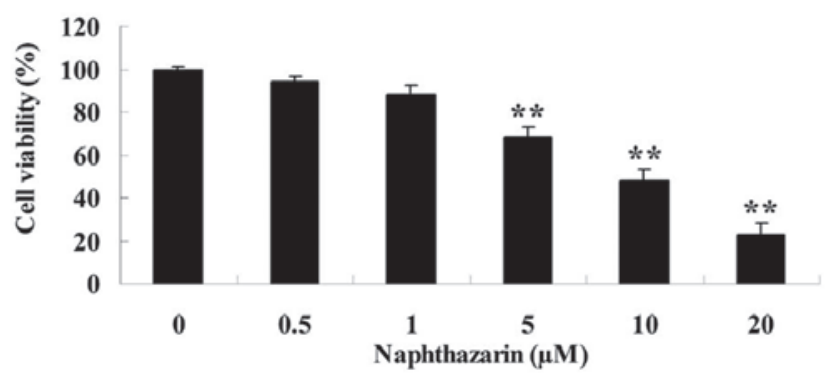

Figure 2. Effect of naphthazarin on cell viability of SW480 cells was analyzed by MTT assay. Treatment with 5, 10 and $20 \mu \mathrm{M}$ naphthazarin for $24 \mathrm{~h}$ significantly decreased cell viability of SW480 cells. ${ }^{* *} \mathrm{P}<0.01$ vs. $0 \mu \mathrm{M}$ naphthazarin treatment group. 3-(4,5-dimethylthiazol-2-yl)-2,5-diphenyltetrazolium bromide.

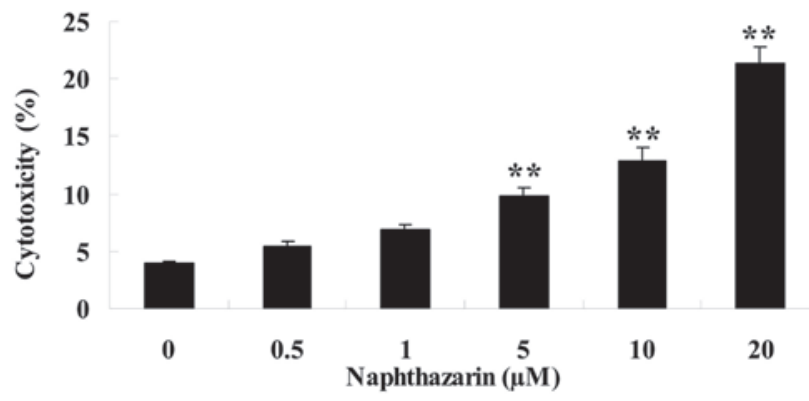

Figure 3. Effect of naphthazarin on SW480 cell cytotoxicity was analyzed by lactate dehydrogenase assay. Treatment with 5,10 and $20 \mu \mathrm{M}$ naphthazarin for $24 \mathrm{~h}$ significantly increased cell cytoxicity in SW480 cells. ${ }^{* *} \mathrm{P}<0.01 \mathrm{vs.} 0 \mu \mathrm{M}$ naphthazarin treatment group.



Figure 4. Effect of naphthazarin on cell apoptosis of SW480 cells was analyzed by flow cytometry. Treatment with 1 and $5 \mu \mathrm{M}$ naphthazarin for $24 \mathrm{~h}$ significantly increased the apoptotic rate of SW480 cells. ${ }^{* *} \mathrm{P}<0.01 \mathrm{vs.} 0 \mu \mathrm{M}$ naphthazarin treatment group.

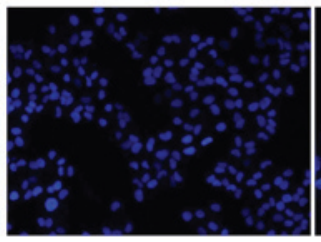

0

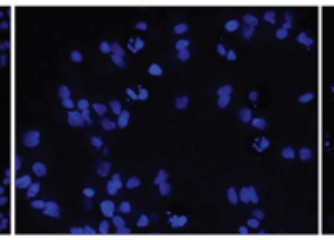

0.5

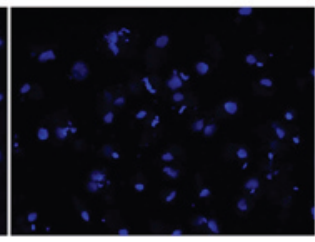

1

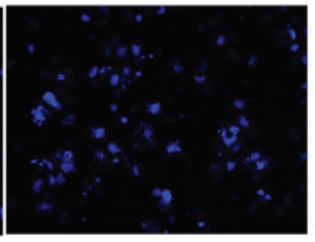

5

Naphthazarin $(\mu \mathrm{M})$

Figure 5. Effect of naphthazarin on nuclear apoptosis of SW480 cells was analyzed by DAPI staining. Treatment with $0.5,1$ and $5 \mu \mathrm{M}$ naphthazarin for $24 \mathrm{~h}$ effectively promoted nuclear apoptosis in SW480 cells compared with the 0- $\mu \mathrm{M}$ naphthazarin treatment group. Magnification, x10.

cells in a dose-dependent manner $(\mathrm{P}<0.01$; Fig. 2). These results indicate that naphthazarin exhibits an anticancer effect on human colorectal cancer cells.

Naphthazarin increases cytotoxicity of SW480 cells. A LDH assay was performed to investigate the effect of naphthazarin on SW480 cell cyotoxicity. Naphthazarin significantly increased cytotoxicity of SW480 cells in dose-dependent manner following treatment with 5, 10 and $20 \mu \mathrm{M}$ naphthazarin for $24 \mathrm{~h}$ (Fig. 3).

Naphthazarin induces apoptosis of SW480 cells. The effect of naphthazarin on SW480 cell apoptosis was investigated. Upon 

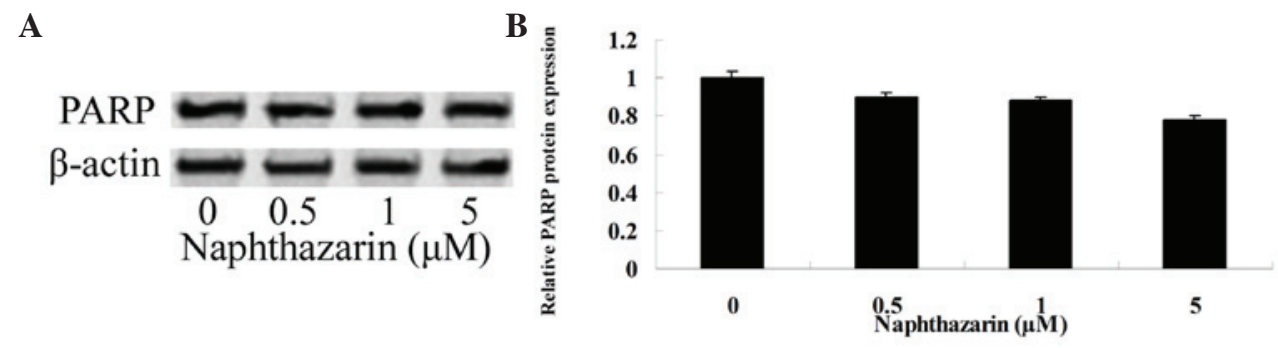

Figure 6. Effect of naphthazarin on PARP of SW480 cells was analyzed by western blotting. (A) Western blot analysis and (B) quantification revealed no evident significant changes in PARP expression following $24 \mathrm{~h}$ treatment with $0.5,1$ and $5 \mu \mathrm{M}$ naphthazarin. PARP, poly (ADP ribose) polymerase.

A

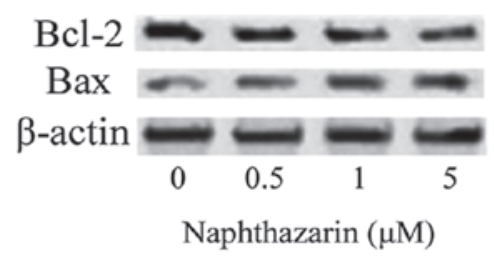

B

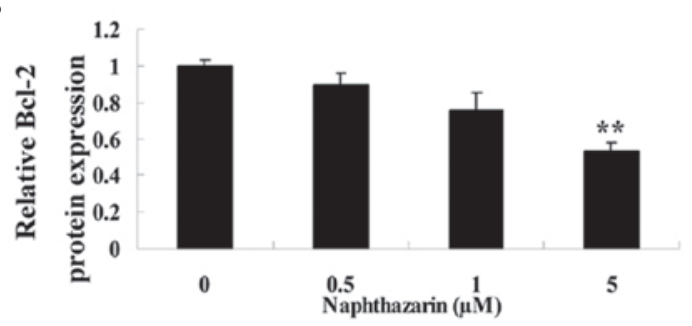

C

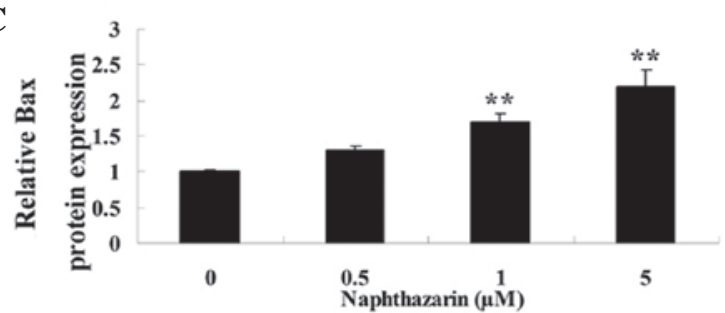

Figure 7. Effect of naphthazarin on Bcl-2 and Bax protein expression in SW480 cells was analyzed by (A) western blot analysis. Quantification of western blotting revealed that (B) Bcl-2 expression was significantly decreased following $24 \mathrm{~h}$ treatment with $5 \mu \mathrm{M}$ naphthazarin while (C) Bax expressions was significantly increased following $24 \mathrm{~h}$ treatment with 1 and $5 \mu \mathrm{M}$ naphthazarin in $\mathrm{SW} 480$ cells ${ }^{* *} \mathrm{P}<0.01$ vs. $0 \mu \mathrm{M}$ naphthazarin treatment group. Bcl-2, B-cell lymphoma 2; Bax, B-cell associated X protein.

treatment with 1 and $5 \mu \mathrm{M}$ naphthazarin for $24 \mathrm{~h}$, the rate of cell apoptosis was significantly increased in SW480 cells in a dose-dependent manner (Fig. 4).

Naphthazarin induces nuclear apoptosis in SW480 cells. SW480 cells were stained with DAPI and observed under a fluorescent microscope to investigate the effect of naphthazarinon nuclear apoptosis. Nuclear apoptosis was observed in SW480 cells following treatment with $0.5,1$ and $5 \mu \mathrm{M}$ naphthazarin for $24 \mathrm{~h}$ (Fig. 5).

Effect of naphthazarin on PARP of SW480 cells. To determine whether PARP is associated with the effects of naphthazarin on cell viability and apoptosis in SW480 cells, PARP protein expression was evaluated by western blotting. As shown in Fig. 6, treatment with $0.5,1$ and $5 \mu \mathrm{M}$ naphthazarin for $24 \mathrm{~h}$

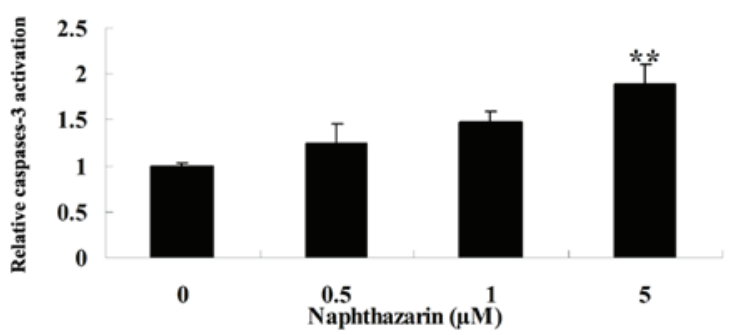

Figure 8. Effect of naphthazarin on caspase-3 activation in SW480 cells was analyzed by casapse-3 activation assay. Treatment with $5 \mu \mathrm{M}$ naphthazarin for 24 h significantly increased casapse- 3 activation in SW480 cells. ${ }^{* *} \mathrm{P}<0.01$ vs. $0 \mu \mathrm{M}$ naphthazarin treatment group.

decreased PARP protein expression, however, no significant differences were observed when compared with the control group.

Naphthazarin decreases Bcl-2 and increases Bax expression in SW480 cells. To further investigate the anticancer effect of naphthazarin, the protein expression of Bcl-2 and Bax in human colorectal SW480 cancer cells was analyzed by western blotting following naphthazarin treatment (Fig. 7A). The results revealed that treatment with $5 \mu \mathrm{M}$ naphthazarin for $24 \mathrm{~h}$ significantly decreased Bcl-2 expression in cells compared with the control $(\mathrm{P}<0.01$; Fig. 7B). Furthermore, treatment with 1 and $5 \mu \mathrm{M}$ naphthazarin for $24 \mathrm{~h}$ significantly increased Bax protein expression in a dose-dependent manner compared with the control (Fig. 7C).

Effect of naphthazarin on caspase-3 of SW480 cells. To confirm that potential mechanism of naphthazarin on cell apoptosis of human colorectal cancer cell, we also examined the activation of caspase-3 after naphthazarin treatment with for $24 \mathrm{~h}$. Treatment with $5 \mu \mathrm{M}$ naphthazarin resulted in significantly increased levels of caspase-3 activation in SW480 cells compared with the control (Fig. 8).

\section{Discussion}

Globally, colorectal cancer is the third most common type of malignant tumor, after lung and breast cancer (11). The incidence of colorectal cancer exhibits differences in regional distribution: Incidence is highest in developed countries and regions, such as Australia, New Zealand, Europe and North America, and lower in Asia and Africa (12-14). The highest mortality rates occur in Central and Eastern European countries, and the lowest 
mortality rates are observed in central African regions (15). In China in 2009, colorectal cancer incidence and mortality rates were higher than the world averages: Rates were than lower that observed in Japan, Singapore and South Korea, but higher than that of countries such as Iran, Laos and India $(16,17)$. In the present study, it was demonstrated that naphthazarin significantly decreased cell viability, increased cytotoxicity and induced cellular and nuclear apoptosis of SW480 cells in a dose-dependent manner. Recent studies have demonstrated that naphthazarin induces apoptosis of human breast cancer (18) and gastric cancer cells (19).

PARP is involved in DNA damage recognition and signal transduction: PARP inhibitors can selectively prevent defects in the DNA of tumor cells (20). A previous clinical trial revealed that PARP inhibitors used for the treatment of ovarian cancer patients harboring mutations in breast cancer susceptibility genes achieved a good response rate, with few side effects (21). However, in the present study, treatment with naphthazarin did not affect PARP protein expression levels in SW480 cells. These results indicate that the PARP signaling pathway may not be involved with the anticancer effects of naphthazarin on human colorectal cancer cells.

Colorectal cancer is one of the most common malignant tumors worldwide (22). It has been demonstrated that the occurrence of tumor development depends on the dynamic balance between cell proliferation and apoptosis (23). Caspase-3 is a important apoptotic protein for various cells, and caspase-3 activation can induce apoptosis in cancer cells (24). The Bcl-2 family of apoptosis-related proteins includes important regulatory factors: Bcl-2 inhibits apoptosis, whereas Bax and Bak promote apoptosis. Therefore, changes in expression of these proteins affects the apoptosis of both normal cells and tumor cells $(25,26)$. The results of the present study revealed that naphthazarin promoted Bax expression and inhibited Bcl-2 protein expression, and increased caspase-3 activation in SW480 cells. These results are in accordance with those of Acharya et al (9) who reported that naphthazarin increases the $\mathrm{Bax} / \mathrm{Bcl}-2$ protein ratio in A549 lung cancer cells.

In conclusion, the present study demonstrated that naphthazarin suppressed cell proliferation and induced apoptosis in human colorectal cancer cells via the Bcl-2/Bax signaling pathway. Thus, we hypothesize that naphthazarin may present a potential chemotherapeutic agent for colorectal cancer. However, further studies are required to investigate the mechanisms underlying the anticancer effects of naphthazarin on human colorectal cancers.

\section{References}

1. Sakurai J, Matsui Y, Hiraki T, Iguchi T, Fujiwara H, Gobara H, Mitsuhashi T, Nagasaka T and Kanazawa S: Single center prospective phase II trial of CT-guided radiofrequency ablation for pulmonary metastases from colorectal cancer (SCIRO-1401). Acta Med Okayama 70: 317-321, 2016.

2. Huang L, Xu Y, Cai G, Guan Z and Cai S: Downregulation of S100A4 expression by RNA interference suppresses cell growth and invasion in human colorectal cancer cells. Oncol Rep 27: 917-922, 2012.

3. Kanefendt F, Lindauer A, Kinzig M, Strumberg D, Scheulen ME, Mross K, Fischer R, Moritz B, Sörgel F and Jaehde U: Biomarker response on exposure to sunitinib and its primary metabolite (SU12662) in metastatic colorectal cancer patients. Int J Clin Pharmacol Ther 49: 88-90, 2011.
4. Xu F, Xu L, Wang M, An G and Feng G: The accuracy of circulating microRNA-21 in the diagnosis of colorectal cancer: A systematic review and meta-analysis. Colorectal Dis 17: O100-O107, 2015.

5. Su B, Xu B and Wan J: Correlation between long-term aspirin use and F-fluorodeoxyglucose uptake in colorectal cancer measured by PET/CT. PLoS One 9: e109459, 2014.

6. Cai Q, Lin J, Wei L, Zhang L, Wang L, Zhan Y, Zeng J, Xu W, Shen A, Hong Z and Peng J: Hedyotis diffusa Willd inhibits colorectal cancer growth in vivo via inhibition of STAT3 signaling pathway. Int J Mol Sci 13: 6117-6128, 2012.

7. Josa V, Krzystanek M, Eklund AC, Salamon F, Zarand A, Szallasi Z and Baranyai Z: Relationship of postoperative thrombocytosis and survival of patients with colorectal cancer. Int $\mathrm{J}$ Surg 18: 1-6, 2015

8. Kim MY, Park SJ, Shim JW, Yang K, Kang HS and Heo K: Naphthazarin enhances ionizing radiation-induced cell cycle arrest and apoptosis in human breast cancer cells. Int J Oncol 46: 1659-1666, 2015.

9. Acharya BR, Bhattacharyya S, Choudhury D and Chakrabarti G: The microtubule depolymerizing agent naphthazarin induces both apoptosis and autophagy in A549 lung cancer cells. Apoptosis 16: 924-939, 2011.

10. Choi SY, Son TG, Park HR, Jang YJ, Oh SB, Jin B and Lee J: Naphthazarin has a protective effect on the 1-methyl-4-phenyl-1,2,3,4-tetrahydropyridine-induced Parkinson's disease model. J Neurosci Res 90: 1842-1849, 2012.

11. Kim SJ, Kim HJ, Kim HR, Lee SH, Cho SD, Choi CS, Nam JS and Jung JY: Antitumor actions of baicalein and wogonin in HT-29 human colorectal cancer cells. Mol Med Rep 6: 1443-1449, 2012.

12. Tatsumi S, Matsuoka H, Hashimoto Y, Hatta K, Maeda K and Kamoshida S: Organic cation transporter 2 and tumor budding as independent prognostic factors in metastatic colorectal cancer patients treated with oxaliplatin-based chemotherapy. Int J Clin Exp Pathol 7: 204-212, 2013.

13. Liu Z, Huang Q, Liu G, Dang L, Chu D, Tao K and Wang W: Presence of FOXP3(+)Treg cells is correlated with colorectal cancer progression. Int J Clin Exp Med 7: 1781-1785, 2014.

14. Shimizu D, Ishikawa T, Ichikawa Y, Togo S, Hayasizaki Y, Okazaki Y, Danenberg PV and Shimada H: Prediction of chemosensitivity of colorectal cancer to 5-fluorouracil by gene expression profiling with cDNA microarrays. Int J Oncol 27: 371-376, 2005

15. Krützfeldt J, Rösch N, Hausser J, Manoharan M, Zavolan M and Stoffel M: MicroRNA-194 is a target of transcription factor 1 (Tcf1, HNF1 $\alpha$ ) in adult liver and controls expression of frizzled-6. Hepatology 55: 98-107, 2012.

16. Dimou A, Syrigos KN and Saif MW: Disparities in colorectal cancer in African-Americans vs Whites: Before and after diagnosis. World J Gastroenterol 15: 3734-3743, 2009.

17. Mehrabani D, Shamsdin SA, Dehghan A and Safarpour A: Clinical significance of serum vascular endothelial growth factor and complement $3 \mathrm{a}$ levels in patients with colorectal cancer in southern Iran. Asian Pac J Cancer Prev 15: 9713-9717, 2014.

18. Kim MY, Park SJ, Shim JW, Yang K, Kang HS and Heo K: Naphthazarin enhances ionizing radiation-induced cell cycle arrest and apoptosis in human breast cancer cells. Int J Oncol 46: 1659-1666, 2015

19. Kim JA, Lee EK, Park SJ, Kim ND, Hyun DH, Lee CG, Lee JH, Yang KM, Heo K and Son TG: Novel anti-cancer role of naphthazarin in human gastric cancer cells. Int J Oncol 40: 157-162, 2012.

20. Sung B, Kang YJ, Kim DH, Hwang SY, Lee Y, Kim M, Yoon JH, Kim CM, Chung HY and Kim ND: Corosolic acid induces apoptotic cell death in HCT116 human colon cancer cells through a caspase-dependent pathway. Int J Mol Med 33: 943-949, 2014.

21. Hochster H, Wadler S, Runowicz C, Liebes L, Cohen H, Wallach R, Sorich J, Taubes B and Speyer J: Activity and pharmacodynamics of 21-Day topotecan infusion in patients with ovarian cancer previously treated with platinum-based chemotherapy. New York Gynecologic Oncology Group. J Clin Oncol 17: 2553-2561, 1999

22. Eng C, Bessudo A, Hart LL, Severtsev A, Gladkov O, Müller L, Kopp MV, Vladimirov V, Langdon R, Kotiv B, et al: A randomized, placebo-controlled, phase $1 / 2$ study of tivantinib (ARQ 197) in combination with irinotecan and cetuximab in patients with metastatic colorectal cancer with wild-type KRAS who have received first-line systemic therapy. Int J Cancer 139: 177-186, 2016. 
23. Prasad S, Yadav VR, Sung B, Reuter S, Kannappan R Deorukhkar A, Diagaradjane P, Wei C, Baladandayuthapani V, Krishnan S, et al: Ursolic acid inhibits growth and metastasis of human colorectal cancer in an orthotopic nude mouse model by targeting multiple cell signaling pathways: Chemosensitization with capecitabine. Clin Cancer Res 18: 4942-4953, 2012.

24. Dastjerdi MN, Rarani MZ, Valiani A and Mahmoudieh M: The effect of adenosine A1 receptor agonist and antagonist on p53 and caspase 3, 8, and 9 expression and apoptosis rate in MCF-7 breast cancer cell line. Res Pharm Sci 11: 303-310, 2016.
25. Song J, Peng XL, Ji MY, Ai MH, Zhang JX and Dong WG: Hugl-1 induces apoptosis in esophageal carcinoma cells both in vitro and in vivo. World J Gastroenterol 19: 4127-4136, 2013.

26. Chudecka-Głaz AM, Cymbaluk-Płoska AA, Menkiszak JL, Sompolska-Rzechuła AM, Toloczko-Grabarek AI and Rzepka-Górska IA: Serum HE4, CA125, YKL-40, bcl-2, cathepsin-L and prediction optimal debulking surgery, response to chemotherapy in ovarian cancer. J Ovarian Res 7: 62,2014 